\title{
Interactive comment on "Hydrology and beyond: The scientific work of August Colding revisited" by Dan Rosbjerg
}

\section{Dan Rosbjerg}

daro@env.dtu.dk

Received and published: 19 July 2020

R\#1: Several figures have poor quality and are difficult or impossible to interpret (Figure 3 and Figures $6-11$ ). Is it possible to scan the originals or better copies of the originals? The paper would be greatly improved with better figures. Explanatory captions would also be helpful.

Reply: Unfortunately, the quality of the figures in the pdfs of Colding's manuscripts I could get access to was rather poor. In my processing, the figure quality may have become even worse. I will try to improve the quality as much as possible. Moreover, I shall expand figure captions where appropriate.

R\#1: Line 55-57 The author makes an important comment on the term "force". This 
could preferably be placed a little earlier, perhaps (slightly modified) as a footnote to line 44 . With the present organization the reader gets confused by the use of "force" in the preceding paragraphs.

Reply: As requested, I shall introduce the meaning of the term "force" earlier in the paper.

R\#1: Line 121-123 The reader gets curious about data or other evidence behind the statement that "The monitoring efforts proved excellent for assessing the amount of evaporation and its dependence on precipitation and seasonality." Please describe Colding's evaluation.

Reply: I shall try to clarify and present Colding's evaluation in a better way.

R\#1: Line 150-152 What type of "water loss from a pipe with flowing water" was considered? Please explain.

Reply: By mistake I wrote "water loss" instead of "heat loss". I shall correct.

R\#1: Line 215 and Figure 9 Did he really find a parabolic piezometric surface for a confined aquifer draining to open water? The shape of such surface is determined by the geometry of the confined aquifer (and the boundary conditions). The parabolic surface must be a special case. For an unconfined aquifer, on the other hand, the water table may have a parabolic surface (unconfined aquifer on a horizontal bottom, without recharge). Due to the poor quality of Figure 9 it is not possible to evaluate the experiment. Please improve the copy and explain what the figure shows.

Reply: Approximately, he found a parabolic piezometric surface, resembling that steady, uniform recharge to a horizontal confined layer of constant thickness with fixed boundary conditions leads to a parabolic solution.

Printer-friendly version

R\#1: There are some proof reading errors. See lines 153, 191, 219, 226, and 315 (1976 should be 1876). 
Reply: The errors will be corrected.

Thanks for the comments, they have been very helpful.

HESSD

Interactive comment on Hydrol. Earth Syst. Sci. Discuss., https://doi.org/10.5194/hess-2020$171,2020$.

Interactive

comment 